\title{
Study of the hematological scoring system and C-reactive protein (CRP) in determining Neonatal sepsis
}

\author{
Ramesh Godbole C. ${ }^{1 *}$, Ramdas Joshi S. ${ }^{2}$, Jaison J. ${ }^{3}$ \\ DOI: https://doi.org/10.17511/jopm.2020.i02.11 \\ 1* Chandrahas Ramesh Godbole, Associate Professor, Department of Pathology, MIMER Medical College, Talegaon, Maharashtra, India. \\ 2 Sneha Ramdas Joshi, Professor and Head of Department, Department of Pathology, MIMER Medical College, Talegaon, Maharashtra, India. \\ 3 Janice Jaison, Associate Professor, Department of Pathology, MIMER Medical College, Talegaon, Maharashtra, India.
}

Background: Laboratory sepsis markers play an important role in the assessment of a neonate with clinical signs of a probable infection with. C - reactive protein (CRP), Blood culture (BC), Hematological Scoring System (HSS) are three well-identified parameters designated for the investigation of Neonatal Sepsis or infection. Material and Methods: The current study was a prospective hospital-based cross-sectional study carried out at the Department of Pathology, MIMER Medical College, Talegaon (D), Maharashtra, India. Neonates with features suggestive of sepsis and Neonates with recent maternal infection were included in the study. Sensitivity, specificity, Positive Predictive Values (PPVs) and Negative Predictive Values (NPVs) were calculated for each parameter. Results: A total of 40 neonates suspected of having sepsis were enrolled in the current study. In the current study, blood culture was positive in 10 cases (25\%), out of which 6 (60\%) were Grampositive and $4(40 \%)$ were Gram-negative, whereas 30 cases were found to be negative for blood culture. The mean CRP levels in positive culture cases were $85.7 \pm 17$, whereas, in the negative culture case, the mean CRP Levels were 38.7 \pm 23 , whereas the mean value in control was $5.88 \pm 0.72$. Conclusion: HSS is a simple, easy, cheap, and rapid adjunct for the diagnosis of clinically suspected cases of neonatal sepsis. C-reactive protein values correlate well with HSS in predicting sepsis. However, C-reactive protein does not have any advantage over HSS, either as a single test or in combination.

Keywords: Neonatal sepsis, C - reactive protein (CRP), Blood culture (BC), Hematological Scoring System (HSS)

Corresponding Author

Chandrahas Ramesh Godbole, Associate Professor, Department of Pathology, MIMER Medical College, Talegaon, Maharashtra, India.

Email: chandrahasgod@yahoo.cor

\section{How to Cite this Article}

To Browse

Godbole RC, Joshi SR, Jaison J. Study of the hematological scoring system and C-reactive protein (CRP) in determining Neonatal sepsis. Trop J Pathol Microbiol. 2020;6(2):181-190.

Available From

https://pathology.medresearch.in/index.php/jopm/ar ticle/view/446

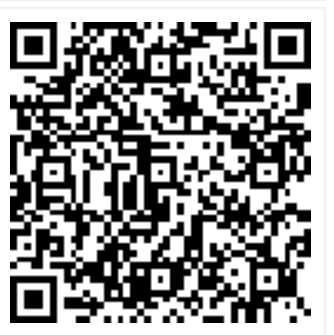

Manuscript Received 20-01-2020

Conflict of Interest No

Review Round 1
30-01-2020
Funding
Nil

Review Round 1

Nil

Review Round 2
06-02-2020
Ethical Approval
Yes

Review Round 2

Yes
Review Round 3

Plagiarism X-checker $13 \%$
Accepted 12-02-2020

(C) 2020 by Chandrahas Ramesh Godbole, Sneha Ramdas Joshi, Janice Jaison and Published by Siddharth Health Research and Social Welfare Society. This is an Open Access article licensed under a Creative Commons Attribution 4.0 International License https://creativecommons.org/licenses/by/4.0/ unported [CC BY 4.0]. 


\section{Introduction}

Neonatal sepsis is defined as an aggressive bacterial infection occurring in the first 4 weeks of life. The incidence of neonatal sepsis varies from 11-24.5 /1000 live births in India [1]. The clinical pointer of sepsis in new-born infants is usually non-specific.

Because of the high morbidity and mortality which is related to neonatal sepsis $[2,3,4]$, antibiotic therapy is started soon after the commencement of the symptoms before the diagnosis is long-established by blood culture.

The use of effective antimicrobial therapy has evidently reduced neonatal mortality. However, there is a need for a rapid test that can identify infected neonates at the time of initial valuation thus sparing the uninfected ones from redundant antibiotic therapy.

The current practice of starting empirical antibiotic therapy in all neonates showing infection-like symptoms results in their exposure to adverse drug effects, nosocomial complications, and in the emergence of resistant strains. [5].

Sepsis results from the complex interaction between the invading microorganism and the host immune, inflammatory, and coagulation response. [6,7] Inflammatory cytokines (TNF-a, IL-1 $\beta$, IL-6, IL-8, IL$15, \mathrm{IL}-18, \mathrm{MIF})$ and growth factors (IL-3, CSFs), and their secondary mediators, including nitric oxide, thromboxanes, leukotrienes, platelet-activating factor, prostaglandins, and complement, cause activation of the coagulation cascade, the complement cascade, and the production of prostaglandins, leukotrienes, proteases, and oxidants. [8]

Laboratory sepsis markers represent a helpful tool in the evaluation of a child with clinical signs and complement the evaluation of a neonate with a potential infection. During the last decades' efforts were done to improve laboratory sepsis diagnosis and a variety of the above-mentioned markers and more were studied with different success.

Despite the promising results for some of them, the current evidence suggests that none of them can consistently diagnose $100 \%$ of infected cases.

C - reactive protein (CRP), Blood culture (BC), Hematological Scoring System (HSS) are three wellidentified parameters indicated for analysis of Neonatal Sepsis or infection.
C-reactive protein (CRP) is the most extensively studied acute phase reactant so far and despite the ongoing rise (and fall) of new infection markers it still remains the preferred index in many neonatal intensive care units. C-reactive protein was first described in 1930 by Tillet and Francis at Rockefeller University [10]. C-reactive protein is an acute phase and an inflammatory marker that is synthesized in the liver in response to inflammatory cytokines. The level of C-reactive protein rises rapidly with a peak level in 6 hours, even up to thousands of folds during an acute response. It has a short half-life of 19 hours, so the level falls rapidly once the source is removed $[11,12,13]$. Thus, the CRP level is also a useful marker in determining the duration of antibiotic therapy. These features distinguish CRP from other acute-phase proteins and with the availability of rapid assay method, it has potential importance in diagnosing neonatal sepsis. Unlike blood culture, the CRP level is not affected by prior antibiotic therapy $[14,15,16]$, so it may be particularly useful in developing countries like India, where a significant number of neonates may have been given antibiotics by local doctors before presentation at the hospital.

Blood Culture is considered the Gold Standard in detecting Neonatal Infections. But still, the consequences of Blood Culture get affected by blood volume, usage of pre-natal antibiotics, level of bacteremia and laboratory facilities. Hence, its rate of positivity is relatively low. Also, in the case of Sample volume, the mentioned minimal blood volume for blood culture in new-borns is only $1 \mathrm{ml}$. However, in most cases, the sample volume collected is found to be only $0.5 \mathrm{ml}$.In low-colony count bacteremia, around $60 \%$ of blood cultures will be falsely negative with $0.5 \mathrm{ml}$ sample volumes. Multiple blood culture could benefit the augmentation of this test, but past studies conducted in the neonatal period have shown that diagnostic tests like blood culture are timeconsuming as well as show conflicting results $[17,18]$.

Hematological Scoring System (HSS) can improvise the diagnostic accuracy of the complete blood cell count as the screening test for neonatal sepsis. But it is challenging to interpret peripheral smears and hemogram parameters in the neonatal period because they vary considerably with the day of life and the gestational age (preterm or otherwise).

Low values of white blood cells, low values of absolute neutrophil counts and high immature/ total 
Ratio are related to early onset of sepsis in infants. High or low white blood cell counts, high absolute neutrophil counts, high immature /total ratio and low platelet counts are related to the late onset of sepsis.

Though all of these mentioned parameters are linked with sepsis or infection, all of these values separately have low sensitivities. Monroe devised a criterion that used three parameters of total PMN count, immature PMN count and I: T ratio, whereas in this hematologic scoring system.

Here, the current study undertake the study to evaluate the performance of the hematological scoring system (HSS) of Rodwell et al. (1988) in 110 neonates for the early detection of sepsis in high-risk infants, which should improve the diagnostic accuracy of the complete blood cell count as a screening test $[19,20]$.

The present study was conducted to review the role of HSS and CRP as a diagnostic parameter in neonatal infections. The purpose was to obtain a range of tests that are fast, efficient, feasible and practically possible for laboratories with small setups in the developing as well as developed countries for diagnosis of neonatal sepsis.

\section{Material and Methods}

Type of study: The current study was a prospective hospital-based cross-sectional study carried out at the Department of Pathology during months of March and April 2019.

Sample size: A total of 40 neonates suspected of having sepsis were enrolled in the current study

Inclusion criteria:

- Neonates with clinical features suggestive of sepsis.

- Neonates with recent maternal infections.

Exclusion criteria:

- Intraventricular hemorrhage

- Meconium aspiration

- Pneumothorax

- Those who underwent surgery

- Birth asphyxia

- Antibiotic therapy prior to admission

Study procedure

Relevant maternal and neonatal histories were
Recorded in designed and pretested proforma. Blood samples (2 $\mathrm{mL}$ ) were collected from the peripheral venous puncture within 24 hours of admission before the initiation of antibiotic therapy.

Under complete aseptic conditions, $0.5-1 \mathrm{ml}$ of the blood sample was obtained. Sepsis workup involved complete blood counts along with hematological score (Rodwell's) and microbial culture. Uncorrected WBC count, platelet count was measured using 5 part fully automated analyzer.

Neutrophils were classified as band forms when there was no nuclear segmentation or when the width of the nucleus at any constriction was not less than one-third the widths at its widest portion.

Band forms together with less mature cell forms were classified as immature Polymorphonuclear (PMN) leukocytes. Using these values, I: M and I: T ratios were computed. Immature neutrophils include promyelocyte myelocyte, metamyelocyte and band form. The hematological findings were analyzed according to the Haematologic Scoring System (HSS) of Rodwell's et al,[20] which includes.

- White Blood Cell (WBC) count and it's differential.

- Platelet count, N-RBCs (To correct total WBC's count).

- Assessment of degenerative and toxic changes in PMNs.

The HSS assigns a score of one for each of the seven criteria found to be significantly associated with sepsis with one exception. An abnormal total PMN count is assigned a score of 2 instead of 1 as shown in the [Table 1]. Sensitivity, specificity, positive and negative predictive values will be evaluated for each of the seven criteria of HSS. Blood Culture and CRP estimation were done as per the standard protocol.

Diagnosis

Proven (definitive) sepsis

Blood culture positive cases with either positive clinical signs or positive septic screen. Following parameters

Were considered significant in septic screen:

Total WBC: $\leq 5000$ cells/c.mm.

I/T Ratio: $\geq 0.2$

CRP: $\geq 6 \mathrm{mg} / \mathrm{I}$ 
Band cells: $\geq 20 \%$.

Platelet count $\leq 1,50,000$ cells $/ \mathrm{mm} .3$

Considered as a positive septic screen if any two or more of the above criteria are met.

Probable sepsis

If the septic screen was positive or clinically symptomatic but blood culture negative.

No sepsis

Sepsis screen, as well as blood culture, are negative and baby is asymptomatic

\section{Statistical Analysis}

The data obtained were tabulated on Microsoft excel spreadsheets and analyzed. The data were expressed in terms of Mean \pm SD and percentages.

Sensitivity, specificity, Positive Predictive Values (PPVs) and Negative Predictive Values (NPVs) were calculated for each parameter.

Table 1: Haematologic scoring system (HSS).

\begin{tabular}{|l|l|l|}
\hline \multicolumn{2}{|c|}{ Hematological scoring system } & Score \\
\hline Criteria & Abnormality & 1 \\
\hline ANC (cells/cumm) & $<20,000$ & \\
\hline Immature neutrophil count & $<1800$ & 1 \\
\hline (cells/cumm) & $<1200$ & 1 \\
\hline I:T & & \\
\hline I:M & $\geq 0.2$ & 1 \\
\hline Platelet count (cells/cumm) & $\geq 0.3$ & 1 \\
\hline Degenerative changes in & $<150,000$ & 1 \\
\hline neutrophils & Toxic granules cytoplasmic & 1 \\
\hline I: T - Immature to total neutrophils ratio; & vacuoles & \\
I: $M$ M - Immature to mature neutrophils ratio & \\
\hline ANC - absolute neutrophil count & & \\
\hline
\end{tabular}

\section{Results}

In the current study, blood culture was positive in 10 cases $(25 \%)$, out of which $6(60 \%)$ were Grampositive and $4(40 \%)$ were Gram-negative, whereas 30 cases were found to be negative for blood culture. If the bacteriological profile of the culture is assumed to be the standard outcome, 10 cases are labeled as the definitive sepsis cases.

Klebsiella Pneumonia, Pseudomonas, Enterococcus, Staphylococcus aureus, and $E$. coli were the infections observed in the positive culture (Table 2 ).
Table 2: Distribution of cases in accordance with the culture positivity $(n=40)$.

\begin{tabular}{|l|l|}
\hline \multicolumn{1}{|c|}{ Culture } & \multicolumn{1}{c|}{ Number } \\
\hline Positive & $10(25 \%)$ \\
\hline Gram-Positive & $6(60 \%)$ \\
\hline Gram-Negative & $4(40 \%)$ \\
\hline Negative & 30 \\
\hline Total & 40 \\
\hline
\end{tabular}

The mean CRP levels in positive culture cases were $85.7 \pm 17$, whereas, in the negative culture cases, the mean CRP Levels were $38.7 \pm 23$, whereas the mean value in control was $5.8 \pm 0.72$, which further indicates the positive culture cases under proven sepsis category (Table 3 ).

Table 3: Mean CRP levels at 72 hours for the diagnosis of neonatal sepsis $(n=40)$.

\begin{tabular}{|c|c|c|c|}
\hline \multirow{2}{*}{$\begin{array}{l}\text { Mean Value of Control } \\
\qquad(\mathrm{n}=20)\end{array}$} & \multicolumn{2}{|c|}{ Mean Value of Cases $(n=40)$} & \multirow[t]{2}{*}{ Reference } \\
\hline & $\begin{array}{l}\text { Positive Culture } \\
(n=10)\end{array}$ & $\begin{array}{l}\text { Negative Culture } \\
(n=30)\end{array}$ & \\
\hline $5.88 \pm 0.72$ & $85.9 \pm 1.27$ & $38.37 \pm 2.31$ & $0-6 \mathrm{mg} / \mathrm{L}$ \\
\hline
\end{tabular}

The commonest age in the cases was 6-10 days and $\leq 5$ days in both the positive and negative culture cases. $6(60 \%)$ of positive culture cases were under $6-10$ days while 13 (43.3\%) of cases were $\leq 5$ days (Table 4).

Table-4: Age-wise distribution of Culture results $(n=40)$

\begin{tabular}{|l|l|l|}
\hline \multicolumn{1}{|c|}{ Age (in Days) } & \multicolumn{2}{c|}{ Culture sensitivity } \\
\cline { 2 - 3 } & Positive & Negative \\
\hline$\leq 5$ Days & $3(30 \%)$ & $13(43.3 \%)$ \\
\hline $6-10$ Days & $6(60 \%)$ & $13(43.3 \%)$ \\
\hline $11-15$ Days & & $2(6.66 \%)$ \\
\hline $16+$ Days & $1(10 \%)$ & $2(6.66 \%)$ \\
\hline
\end{tabular}

Based on Rodwell's scoring system, neonates could be classified as sepsis to be unlikely Score Interpretation $\leq 2$ Sepsis is unlikely in 4 cases, possible in 11 cases and very likely in 25 cases (Table 5 and Table 6).

Table 5: HSS Profile of Neonates $(\mathrm{N}=40)$

\begin{tabular}{|l|l|l|}
\hline \multicolumn{1}{|c|}{ Score } & \multicolumn{1}{|c|}{ Interpretation } & \multicolumn{1}{c|}{ Cases } \\
\hline$\leq 2$ & Sepsis is unlikely & 4 \\
\hline 3 or 4 & Sepsis is possible & 11 \\
\hline$\geq 5$ & Sepsis is very likely & 25 \\
\hline
\end{tabular}

Table 6: Interpretation of HSS

\begin{tabular}{|l|l|l|l|}
\hline \multicolumn{1}{|c|}{ HSS } & \multicolumn{1}{|c|}{ Positive Culture } & \multicolumn{1}{c|}{ Negative Culture } & Total \\
\hline$\leq 2$ & 0 & 4 & 4 \\
\hline 3 or 4 & 0 & 11 & 11 \\
\hline$\geq 5$ & 10 & 15 & 25 \\
\hline
\end{tabular}


The current study showed 10 neonates with positive culture, of which all of them had a HSS of $\geq 6$ (Table 7). The sensitivity, specificity, PPV and NPV of HSS with cut-off score of 6 in predicting sepsis was $33.3 \%, 56.6 \%, 62.5 \%, 100 \%$.

Similarly, the sensitivity, specificity, PPV and NPV of HSS with cut-off score of 5 in predicting sepsis was $33.3 \%$, 40\%, 40\%, 100\%. , the sensitivity, specificity, PPV and NPV of HSS with cut-off score of 4,3 and 2 in predicting sepsis was $33.3 \%, 30 \%$, $32.2 \%, 33.3 \%, 13.3 \%, 27 \%, 33.3 \%, 6.66 \%, 25 \%$ (Table 8).

Table 7: Diagnostic Accuracy of HSS.

\begin{tabular}{|l|l|l|l|}
\hline HSS & \multicolumn{1}{|c|}{ Positive Culture } & \multicolumn{1}{|c|}{ Negative Culture } & \multicolumn{1}{|c|}{ Total } \\
\hline$\geq 6$ & 10 & 6 & 16 \\
\hline$<6$ & - & 17 & 17 \\
\hline$\geq 5$ & 10 & 15 & 25 \\
\hline$<5$ & - & 12 & 12 \\
\hline$\geq 4$ & 10 & 21 & 31 \\
\hline$<4$ & - & 9 & 9 \\
\hline$\geq 3$ & 10 & 27 & 37 \\
\hline$<3$ & - & 4 & 4 \\
\hline$\geq 2$ & 10 & 29 & 39 \\
\hline$<2$ & - & 2 & 2 \\
\hline Total & 10 & 30 & 40 \\
\hline
\end{tabular}

Table 8: Diagnostic accuracy of different haematological scores.

\begin{tabular}{|l|l|l|l|l|}
\hline \multicolumn{1}{|c|}{ HSS } & \multicolumn{1}{c|}{ Sensitivity } & \multicolumn{1}{c|}{ Specificity } & \multicolumn{1}{c|}{ PPV } & \multicolumn{1}{c|}{ NPV } \\
\hline HSS $>6$ & $33.3 \%$ & 56.6 & 62.5 & 100 \\
\hline HSS $>5$ & $33.3 \%$ & 40 & 40 & 100 \\
\hline HSS $>4$ & $33.3 \%$ & $30 \%$ & 32.2 & 100 \\
\hline HSS $>3$ & $33.3 \%$ & 13.3 & 27 & 100 \\
\hline HSS $>2$ & $33.3 \%$ & $6.66 \%$ & 25 & 100 \\
\hline
\end{tabular}

Out of the 10 positive cultured samples from the neonates, 3 had normal I: T Ratio and 7 had increased I: T Ratio. The Sensitivity, Specificity, PPV, and NPV of increased I: T Ratio in predicting sepsis was observed to be $70 \%, 100 \%, 100 \%, 90.0 \%$.

The number of neonates that had increased PMN count was 10, with Sensitivity, Specificity, PPV, and NPV of increased PMN Count in predicting sepsis was observed to be $100 \%, 13.3 \%, 27.77,100 \%$.

In the current study, 7 neonates had increased I: T Ratio with Sensitivity, Specificity, PPV, and NPV of increased $\mathrm{I}$ : $\mathrm{T}$ Ratio in predicting sepsis was observed to be $70 \%, 100 \%, 100 \%, 90.0 \%$.

The number of neonates with increased Total WBC Count was found to be 10 with Sensitivity,
Specificity, PPV, and NPV of Total WBC Count in predicting sepsis were observed to be $100 \%, 30 \%$, $32.25 \%$, $100 \%$. The number of neonates with immature PMN Count was 10 with Sensitivity, Specificity, PPV, and NPV of immature PMN Count in predicting sepsis was observed to be $100 \%, 13.3 \%$, $27.77 \%, 100 \%$.

Degenerative changes were observed in 10 neonates with Sensitivity, Specificity, PPV, and NPV of Degenerative Changes in predicting sepsis was observed to be $100 \%, 13.3 \%, 27.77,100 \%$.

The reduction in platelet count was observed in 10 patients with Sensitivity, Specificity, PPV, and NPV of platelet count was observed to be $100 \%, 43.3 \%$, 37.03\%, 100\% (Table 9 and Table 10).

Table 9: Diagnostic accuracy of different haematological parameters in predicting sepsis.

\begin{tabular}{|c|c|c|c|c|}
\hline Characteristics & I: T Ratio & $\begin{array}{l}\text { Positive } \\
\text { Culture }\end{array}$ & $\begin{array}{c}\text { Negative } \\
\text { Culture }\end{array}$ & | Total \\
\hline \multirow[t]{2}{*}{ I:T: PMN Ratio } & Normal & 3 & 30 & 33 \\
\hline & Increased & 7 & 0 & 7 \\
\hline \multirow[t]{2}{*}{ Total PMN Ratio } & Normal & - & - & - \\
\hline & Increased & 10 & 30 & 40 \\
\hline \multirow[t]{2}{*}{ I:M PMN Ratio } & $\leq 0.3$ & - & 24 & 26 \\
\hline & $\geq 0.3$ & 10 & 6 & 16 \\
\hline \multirow{2}{*}{$\begin{array}{l}\text { Immature PMN } \\
\text { Count }\end{array}$} & Normal & - & 4 & 4 \\
\hline & Increased & 10 & 26 & 36 \\
\hline \multirow[t]{2}{*}{ Total WBC Count } & Normal & & 9 & 9 \\
\hline & Increased & 10 & 21 & 31 \\
\hline \multirow{2}{*}{$\begin{array}{l}\text { Degenerative } \\
\text { Changes }\end{array}$} & Present $\geq 3$ & 10 & 26 & 36 \\
\hline & Absent & - & 4 & 4 \\
\hline \multirow[t]{2}{*}{ Platelet Count } & $\begin{array}{l}\text { Reduced } \\
\leq 100,000 / \mu \mathrm{L}\end{array}$ & 10 & 17 & 27 \\
\hline & $\begin{array}{l}\text { Normal }>100,000 / \\
\mu \mathrm{L}\end{array}$ & - & 13 & 13 \\
\hline
\end{tabular}

Table 10: Association of the individual haematological parameters with neonatal sepsis.

\begin{tabular}{|l|l|l|l|l|}
\hline \multicolumn{1}{|c|}{ Parameters } & Sensitivity & Specificity & \multicolumn{1}{c|}{ PPV } & \multicolumn{1}{c|}{ NPV } \\
\hline I:T Ratio & $70 \%$ & $100 \%$ & $100 \%$ & $90.0 \%$ \\
\hline Total PMN Ratio & $100 \%$ & - & & - \\
\hline I:M PMN Ratio & $100 \%$ & $80 \%$ & $62.5 \%$ & $92.30 \%$ \\
\hline Immature PMN Count & $100 \%$ & $13.3 \%$ & 27.77 & $100 \%$ \\
\hline Total WBC Count & $100 \%$ & $30 \%$ & 32.25 & $100 \%$ \\
\hline Degenerative Changes & $100 \%$ & $13.3 \%$ & 27.77 & $100 \%$ \\
\hline Platelet Count & $100 \%$ & $43.3 \%$ & 37.03 & $100 \%$ \\
\hline
\end{tabular}

In table 11, HSS values were compared with the mean values of CRP values, the association between 
The two parameters represented the significant relationship. 10 cases of the positive culture with the mean CRP value of $85.9 \pm 1.27$ had an HSS of $\geq 5$, whereas 4 cases of the negative group with the mean CRP value of $7.52 \pm 2.34$ had HSS of $0-2,11$ cases of the negative group with the mean CRP of $25.21 \pm 3.21$ had HSS of 3-4, lastly 15 cases of the negative group with the mean CRP of $56.24 \pm 3.81$ had HSS of $\geq 5$.

Table 11: Haematological score in comparison with CRP value.

\begin{tabular}{|l|l|l|l|}
\hline \multirow{2}{*}{ HSS } & \multicolumn{2}{|c|}{ C Reactive Protein (Mean Value) } & \multirow{2}{*}{ Total cases } \\
\cline { 2 - 3 } & Positive & Negative & \\
\hline $0-2$ & 0 & $7.52 \pm 2.34$ & 4 \\
\hline $3-4$ & 0 & $25.21 \pm 3.21$ & 11 \\
\hline$\geq 5$ & $85.9 \pm 1.27$ & $56.24 \pm 3.81$ & 15 \\
\hline Total & 10 & 30 & 40 \\
\hline
\end{tabular}

Figure 1 represented Leucocytosis with degenerative changes and band forms. Immature polymorphs include promyelocyte, myelocyte, metamyelocytes, and band forms.

Band cell is described as a PMN in which the nucleus is indented by more than one-half, but in which, the isthmus between the lobes is wide enough to reveal two distinct margins with nuclear material in between.

Vacuolization, toxic granulations, and Dohle bodies comprise of degenerative changes.

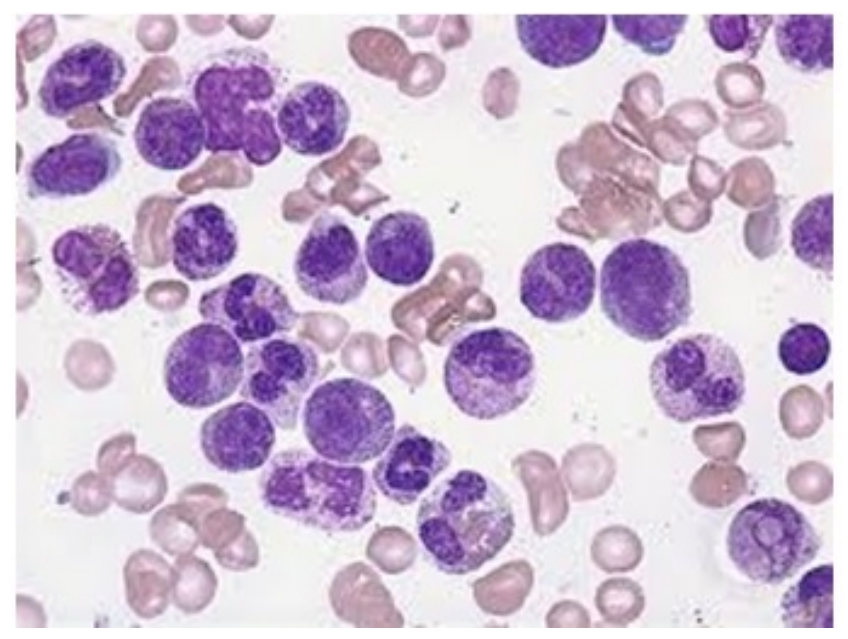

Fig-1: Leucocytosis with degenerative changes and band forms.

Toxic granulations represent the cytoplasmic alterations in peripheral blood neutrophils in response to bacterial infection and have been found to be of greater use in differentiating localized from generalized infection or the development of complications (Figure 2).

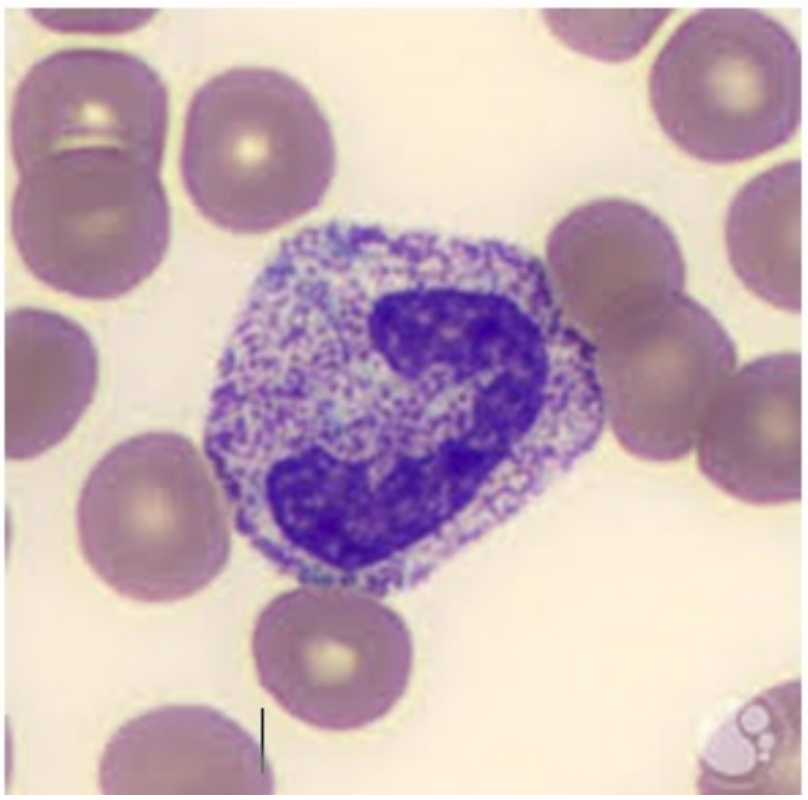

Fig-2: Toxic granulation in neutrophils.

\section{Discussion}

Neonatal sepsis is a serious and potentially lifethreatening condition. In developing countries like India, neonatal sepsis is the major cause of morbidity and mortality in new-born. Risk is increased very much again because of noninstitutional delivery and poor postnatal follow-up. However early diagnosis and treatment are vital for a favorable outcome. Early diagnosis is a difficult task and based mainly on clinical suspicion. No doubt, blood culture is still the gold standard but because of its non-availability in most peripheral setups, high cost, more chances of contamination and delayed results, a need for more convenient, cost-effective test protocol whose results are available in time is felt. C-reactive protein can fill up this time gap, as this is an important indirect test to diagnose neonatal sepsis. C-reactive protein has some practical advantages: it can be done in all those neonates who are on prior antimicrobial therapy. Despite all this still, it is recommended to rely on both clinical correlations and laboratory findings for confirmed diagnosis [15]. The bacteria isolated from the subject's blood culture were Klebsiella Pneumonia, Pseudomonas, Enterococcus, Staphylococcus aureus, and E. Coli.

A previous study also reported about the most commonly observed etiology associated with neonatal sepsis were Gram-Negative bacteria [21]. Bacteria entering the circulation trigger the body's immune response. The cell membrane and wall contain phosphocholine which can activate the 
Complement system. An activated complement system induces granulocyte, phagocyte, and proinflammatory cytokine production. C-reactive protein is an acute-phase protein synthesized along with the activation of proinflammatory cytokines. The same thing will happen to granulocyte which is also a component of white blood cells [22]. The wide variability in diagnostic values of CRP may have been influenced by sample characteristics, study design, sample size, inclusion criteria, and differences in CRP cut-off points. C-reactive protein levels increase 24 to 48 hours after clinical manifestations appear. In the current study, the mean values of CRP were compared with the positive culture cases and negative culture cases with that of the control cases. The overall comparison was further linked to the reference range. Jave $\mathrm{DL}$ [23] stated that monitoring of CRP over time may be used to in determining the response of the treatment after the primary diagnosis. They were discharged home after 5 days of intravenous antibiotic therapy. Jin Cherdze and colleagues [24,25] concluded in their study that quantitative CRP is a rapid, sensitive diagnostic marker for the identification of sepsis in preterm infants. In the current study, it was observed that CRP is a good indicator of neonatal sepsis as the quantitative status of CRP helped in the identification of neonatal sepsis and also in deciding the line of management of the patient.

The common age distribution in the current study was between 6-10 days and $\leq 5$ days in both the positive and negative culture cases. 6 (60\%) of positive culture cases were under 6-10 days while $13(43.3 \%)$ of cases were $\leq 5$ days. Several studies reported age to be significantly associated with neonatal sepsis $[26,27,28]$. Based on Rodwell's scoring system, neonates were classified as sepsis to be unlikely in 4 cases, possible in 11 cases and very likely in 25 cases. In the current study considering all four parameters i.e. sensitivity, specificity, positive predictive value and negative predictive value, I: T PMN ratio and degenerative changes were the most reliable tests for diagnosing sepsis. An abnormal I: M PMN ratio was highly sensitive in identifying sepsis. Degenerative changes in neutrophils were not found to be a very sensitive indicator of sepsis. Thrombocytopenia was consistently associated with poor prognosis. These findings were in comparison with other studies [2932]. The higher the score, the greater was the likelihood of sepsis. A score $\leq 2$ suggests that sepsis was unlikely.
Protein sepsis markers, such as CRP, should be used in concert with clinical signs and findings to make the diagnosis of neonatal sepsis and formulate a plan for management $[33,34]$. CRP has been used to monitor response to infection and to assist in ruling out an infection. Most of these studies have been done in children, term, or near-term neonates using the lower CRP level cutoffs of $<8 \mathrm{mg} / \mathrm{dL}$ or $<10 \mathrm{mg} / \mathrm{dL}$ [35]. The Committee of Fetus and Newborn of the American Academy of Pediatrics (AAP) in their statement on infants with suspected or proven sepsis have expressed agreement in the utility of inflammatory biomarkers [36]. Although other biomarkers such as PCT may also be used, CRP has been described as a later but more specific marker of infection

The major limitations of the present study were the small size of the subjects. A similar study with a large sample size might be able to provide a more comprehensive outcome on the role of HSS and CRP in neonatal sepsis.

\section{Conclusion}

HSS is a simple, quick, cost-effective tool that can be used as a screening test for early diagnosis of neonatal sepsis. It may aid the clinicians in identifying sepsis and to institute proper antibiotic therapy. Unnecessary exposure of infants to antibiotic therapy can thus be avoided. A hematological score can be obtained by a complete blood count and examination of a peripheral blood smear, thus permitting an objective assessment of hematological changes that occur in a neonate suspected of sepsis. Similarly, it would be fair to say that the estimation of CRP in the diagnosis of neonatal sepsis have emerged and evolve rapidly over the last few years. Combining the estimation of CRP with HSS appears to provide a far more effective tool to be used as a screening method for neonatal sepsis.

\section{What does the study add to the existing knowledge?}

The current study aims to highlight the significant role and association between HSS and CRP in the diagnosis of neonatal sepsis. C-reactive protein values correlate well with HSS in predicting sepsis. However, C-reactive protein along with HSS does promise to establish a more effective tool to be used in the screening of neonatal sepsis. 


\section{Author's contribution}

All the authors, Dr. Chandrahas Ramesh Godbole, Dr. Sneha Ramdas Joshi, and Dr. Janice Jaison contributed equally in the conduct of the study and in the preparation of the manuscript.

\section{Reference}

01. Jaswal RS, Kaushal RK,Goel A, Pathania K. Role of the $\mathrm{C}$-reactive protein in deciding the duration of the antibiotic therapy in neonatal septicaemia. Indian Paediatr. 2003;40(9)800883.

[Crossref]

02. Bizzarro MJ, Raskind C, Baltimore RS, Gallagher PG. Seventy five years of neonatal sepsis at Yale- 1928-2003. Paediatr. 2005;116(3)595602.

doi: [Article:https://doi.org/10.1542/peds.20050552][Crossref]

03. Stoll BJ, Hansen NI, Adams-Chapman I, Fanaroff AA, Hintz SR, Vohr B, et al. Neurodevelopmental and growth impairment among extremely low-birth-weight infants with neonatal infections. JAMA. 2004; 292(19)23572365.

doi:

[Article:https://doi.org/10.1001/jama.292.19.2357] [Crossref]

04. Sucilathangam G, Amuthavalli K, Velvizhi G, Ashihabegum MA, Jeyamurugan T, Palaniappan N. Early diagnostic markers for neonatal sepsiscomparing procalcitonin (PCT) and C-reactive protein (CRP). J Clinic Diagnos Res. $2012 ; 6(4) 627-631$.

[Crossref]

05. Ehl S Gering B, Bartmann P, Högel J, Pohlandt F. C-reactive protein is a useful marker for guiding duration of antibiotic therapy in suspected neonatal bacterial infection. Pediatr. 1997;99(2)216-221.

doi: [Article:https://doi.org/10.1542/peds.99.2.216] [Crossref]

06. Khashabi J, Karamiyar $M$, Taghinejihad $H$, Shirazi M. Use of Serial C-Reactive Protein Measurements for Determination of the Length of Empiric Antibiotic Therapy in Suspected Neonatal Sepsis. Iran J Med Sci. 2004;29(1)3135.

[Crossref]
07. Murray BE. Can antibiotic resistance be controlled?. N Engl J Med. $1994 \mathrm{Apr}$ 28;330(17):1229-30.

doi: $10.1056 /$ NEJM199404283301710 [Crossref]

08. Hotchkiss RS, Karl IE. The pathophysiology and treatment of sepsis. New Engl J Med. $2003 ; 348(2) 138-150$

doi: [Article:https://doi.org/10.1056/nejmra021333] [Crossref]

09. Russell JA. Management of sepsis. New Engl J Med. 2006;355(16)1699-1713.

doi: [Article:https://doi.org/10.1056/nejmra043632] [Crossref]

10. Chirico G, Loda C. Laboratory aid to the diagnosis and therapy of infection in the neonate. Pediatr Rep. 2011;3(1)e1.

doi:

[Article:https://dx.doi.org/10.4081\%2Fpr.2011.e1] [Crossref]

11. Hofer N, Müller W, Resch B. The role of Creactive protein in the diagnosis of neonatal sepsis. Neonatal bacterial infection, 1st ed. 2013:45-58.

[Crossref]

12. Devi D, Kumar R. Role of C-reactive protein in rapid diagnosis of early neonatal sepsis in a tertiary care hospital. J Pediatr Res. 2017;4(07)429-437.

doi:

[Article:https://doi.org/10.17511/ijpr.2017.07.01] [Crossref]

13. Marshal SE. Immunological factors in diseases, In- Boon NA, Cooledge NR, Walker BR, et al, Davidson 's principles and practice of medicine. 20th ed, Churchill Livingstone. 2006, p; 63-91. [Crossref]

14. Tillett WS, Francis T. Serological Reactions in Pneumonia with a Non-Protein Somatic Fraction of Pneumococcus. J Experiment Med. $1930 ; 52(4) 561-571$.

doi:

[Article:https://dx.doi.org/10.1084\%2Fjem.52.4.561] [Crossref]

15. Makkar M, Gupta C, Pathak R, Garg S, Mahajan NC. Performance evaluation of hematologic scoring system in early diagnosis of neonatal sepsis. J Clin Neonatol. 2013;2(1)25-29.

doi

[Article:https://doi.org/10.4103/22494847.109243][Crossref] 
16. Clyne B, Olshaker JS. The C-reactive protein. J Emerg Med. 1999;17(6)1019-1025.

doi: [Article:https://doi.org/10.1016/s07364679(99)00135-3][Crossref]

17. Vera $A Z$, Ochoa TJ. Challenges in the diagnosis and management of neonatal sepsis. J Trop Pediatr. 2015;61(1)1-13.

doi: [Article:https://doi.org/10.1093/tropej/fmu079] [Crossref]

18. Godbole C, Lalla P. Role of C-reactive protein (CRP) in determining neonatal infections. Int $\mathrm{J}$ Clin Biochem Res. 2019;6(3)294-298. doi:

[Article:http://doi.org/10.18231/j.ijcbr.2019.065] [Crossref]

19. Manroe BL, Weinberg AG, Rosenfeld CR, Browne $R$. The neonatal blood count in health and disease i reference values for neutrophilic cells. J Paediatr. 1979;95(1)89-98.

doi: [Article:https://doi.org/10.1016/s00223476(79)80096-7][Crossref]

20. Patel U, Patel VK, Patel NP, Verma J, Ratre BK, Verma SP. To evaluate C- Reactive Protein and other Hematological parameters for diagnosis of Neonatal Sepsis. Int J Med Res Rev. 2014;2(4)311-318.

doi:

[Article:https://doi.org/10.17511/ijmrr.2014.i04.08] [Crossref]

21. Speer CP, Gahr M, Schrotter W. Early diagnosis of neonatal infection. Monatsschr Kinderheilkd. 1985;133(9)665-668.

[Crossref]

22. Pourcyrous M, Bada HS, Korones SB, Baselski V, Wong SP. Significance of serial C-reactive protein responses in neonatal infection and other disorders. Pediatr. 1993;92(3)431-435. [Crossref]

23. Hofer N, Zacharias E, Muller W, Resch B. An update on the use of C-reactive protein in earlyonset neonatal sepsis: current insights and new tasks. Neonatol. 2012;102;25-36.

doi: [Article:https://doi.org/10.1159/000336629] [Crossref]

24. Philip AGS, Hewitt JR. Early diagnosis of neonatal sepsis. Pediatr. 1980;65(5)1036-1041. [Crossref]
25. JinCharadze N, Abelashvili D, McHedlishyili M, Kacharava M. Diagnostic value of C-reactive protein test at early-onset sepsis in preterm infants. Georgian Med News. 2006;(130)87-91. [Crossref]

26. Hisamuddin E, Hisam A, Wahid S, Raza G. Validity of C-reactive protein (CRP) for diagnosis of neonatal sepsis. Pak J Med Sci. $2015 ; 31(3) 527-531$.

doi:

[Article:https://doi.org/10.12669/pjms.313.6668] [Crossref]

27. Jave DL, Waites KB. Clinical applications of Creactive Protien in pediatrics. Pediatr Infect Dis J. $1997 ; 16(8) 735-746$.

doi: [Article:https://doi.org/10.1097/00006454199708000-00003][Crossref]

28. Getabelew A, Aman M, Fantaye E, Yeheyis T. Prevalence of neonatal sepsis and associated factors among neonates in neonatal intensive care unit at selected governmental hospitals in Shashemene Town, Oromia Regional State, Ethiopia, 2017. Int J Pediatr. 2018.

doi: [Article:https://doi.org/10.1155/2018/7801272] [Crossref]

29. Alemu M, Ayana M, Abiy H, Minuye B, Alebachew W, Endalamaw A. Determinants of neonatal sepsis among neonates in the northwest part of Ethiopia: case-control study. Italian J Pediatr. 2019;45(1)150.

doi: [Article:https://doi.org/10.1186/s13052-0190739-2][Crossref]

30. Basu S, Guruprasad, Narang A, Garewal G. Diagnosis of sepsis in the high-risk neonate using a hematologic scoring system. Indian J Hematol Blood Transf. 1999;17(2)32-34. [Crossref]

31. Rodwell RL, Leslie AL, Tudehope DI. Early diagnosis of neonatal sepsis using a hematologic scoring system. J Pediatr. 1988;112(5)761-767. doi: [Article:https://doi.org/10.1016/S00223476(88)80699-1][Crossref]

32. Lacaze-Masmonteil T, Rosychuk RJ, Robinson JL. Value of a single C-reactive protein measurement at $18 \mathrm{~h}$ of age. Arch Dis Child Fetal Neonatal Ed. 2014;99(1)F76-F79.

doi: [Article:https://doi.org/10.1136/archdischild2013-303984][Crossref] 
33. Philip AG, Mills PC. Use of C-reactive protein in minimizing antibiotic exposure- Experience with infants initially admitted to a well-baby nursery. Pediatr. 2000;106(1)E4.

doi: [Article:https://doi.org/10.1542/peds.106.1.e4] [Crossref]

34. Ohlin A, Björkqvist M, Montgomery SM, Schollin J. Clinical signs and CRP values associated with blood culture results in neonates evaluated for suspected sepsis. Acta Paediatr. 2010;99(1)1635-1640.

doi: [Article:https://doi.org/10.1111/j.16512227.2010.01913.x][Crossref]
35. Panigrahi $P$, Chandel DS, Hansen NI, Sharma N, Kandefer S, Parida S, et al. Neonatal sepsis in rural India- timing, microbiology and antibiotic resistance in a population-based prospective study in the community setting. J Perinatol. 2017;37(8)911-921.

doi: [Article:https://doi.org/10.1038/jp.2017.67] [Crossref]

36. Polin RA. Management of neonates with suspected or proven early-onset bacterial sepsis. Pediatr. 2012;129(5)1006-1015.

doi: [Article:https://doi.org/10.1542/peds.20120541][Crossref] 